\title{
Stapling and Section of the Nasogastric Tube during Sleeve Gastrectomy: How to Prevent and Recover?
}

\author{
A. Péquignot ${ }^{a}$ \\ A. Dhahria \\ E. Mensah ${ }^{a}$ \\ P. Verhaeghe ${ }^{a}$ \\ R. Badaoui ${ }^{b}$ \\ C. Sabbagh ${ }^{a}$ \\ J.-M. Regimbeau ${ }^{\mathrm{a}}$ \\ Departments of a Digestive Surgery and ${ }^{b}$ Anesthesiology, Amiens University \\ Hospital and Jules Verne University of Picardy, Amiens, France
}

\section{Key Words}

Sleeve gastrectomy $\cdot$ Nasogastric tube $\cdot$ Complication

\begin{abstract}
Bariatric surgery has become an integral part of morbid obesity treatment with well-defined indications. Some complications, specific or not, due to laparoscopic sleeve gastrectomy (LSG) procedure have recently been described. We report a rare complication unpublished to date: a nasogastric section during great gastric curve stapling. A 44-year-old woman suffered of severe obesity (BMI $36.6 \mathrm{~kg} / \mathrm{m}^{2}$ ) with failure of medical treatments for years. According to already published technique, a LSG was performed. Six hours postoperatively, a nurse removed the nasogastric tube according to the local protocol and the nasogastric tube was abnormally short, with staples at its extremity. Surgery was performed with peroperative endoscopy. In conclusion, this is the first publication of a nasogastric section during LSG. Therefore we report this case and propose a solution to prevent its occurrence. To avoid this kind of accident, we now systematically insert the nasogastric tube by mouth through a Guedel cannula. Then, to insert the calibrating bougie, we entirely withdraw the nasogastric tube.
\end{abstract}

\section{Introduction}

Bariatric surgery has become an integral part of morbid obesity treatment with well-defined indications [1-4]. It even appears as the sole treatment for long-term weight loss stability and regression of morbidities [5-11]. Two types of bariatric surgery are available: restrictive (laparoscopic adjustable gastric banding and laparoscopic sleeve gastrectomy) and malabsorptive (laparoscopic gastric bypass) procedures. Laparoscopic 
sleeve gastrectomy (LSG) is increasingly being recognised as a valid stand-alone procedure for the surgical management of morbid obesity. LSG is becoming more and more popular because this technique is more confortable and more efficient than laparoscopic adjustable gastric banding and causes less morbidity than bypass. During this intervention, two different tubes are used by the anaesthesiologists and introduced through the nose: a nasogastric tube and a calibration silastic tube. The calibration silastic tube, allowing the gastric section, is a full tube and is interesting for avoiding stapling of this tube or narrowing of the stomach tubulisation.

Some complications due to LSG procedure, specific or not, have recently been described $[12,13]$. We report a rare complication unpublished to date: a nasogastric section during great gastric curve stapling.

\section{Case Report}

A 44-year-old woman suffered from severe obesity (BMI $36.6 \mathrm{~kg} / \mathrm{m}^{2}$, weight $88 \mathrm{~kg}$, height $155 \mathrm{~cm}$ ) with failure of medical treatments for years. Her obesity was accompanied by comorbidities, including diabetes mellitus type 2 and metabolic syndrome NCEP-ATP3 [14]. She was thus eligible for bariatric surgery according to the HAS (Haute Autorité de la Santé) guidelines [5]. After a multidisciplinary consulting meeting, we decided to perform a LSG.

The gastric sleeve is created by using a linear stapler. According to already published technique [13-15], the staples are applied alongside a 34-Fr calibrating bougie positioned against the lesser gastric curve. The anaesthesiology team helps to correctly set up the bougie. Before the insertion of the calibrating bougie, the pernasal nasogastric tube is partially removed $(20 \mathrm{~cm})$ from the stomach and positioned in the cavum. Once the bougie is withdrawn, a leak test is performed using intraoperative methylene blue dye through a pernasal nasogastric tube repositioned in the stomach.

Six hours postoperatively, when the patient had come back to the recovery room, the nurse removed the nasogastric tube according to the local protocol. In this case, the nasogastric tube was abnormally short and staples were present at its extremity (fig. 1). The surgeons were informed of this situation. The patient did not present hyperthermia $\left(37.7^{\circ} \mathrm{C}\right)$, tachycardia $(87 \mathrm{bpm})$, abdominal pain (under analgesic drugs) or dyspnoea, but she presented nausea according to the normal postoperative course. Peritoneal syndrome was not present at abdominal palpation. No biologic inflammatory syndrome was found.

After discussion we decided, with the patient's information, to perform an abdominal CT scan. Tomographic imaging showed a nasogastric tube fragment in the antrum (fig. 2). We performed a surgical laparoscopic revision in association with gastric endoscopy. There were no staple line leaks. The abdominal exploration did not find any haematoma or abdominal effusion. The fragment of the nasogastric tube was localised endoscopically. This fragment was incarcerated in the staple line, and endoscopic extraction (fig. 3 ) created a staple line defect. The gastric wall was subsequently repaired by the surgeon and the methylene blue test was negative for staple line leak.

\section{Discussion}

LSG has recently emerged as a reproducible surgical technique effective for long-term weight loss stability with regression of most major associated comorbidities, such as diabetes type 2 . Mortality is lower than $1 \%$. Complications caused by this surgical technique vary from 0 to $10 \%$, with a median estimate of $5.1 \%$, according to studies. The major complication, by its frequency and its consequences, is gastric fistula, blind or draining into a nearby organ. This fistula is most often located at the upper end of the stapling line [13]. To our knowledge, this is the first publication of nasogastric 
section during LSG. Therefore we report this case and propose a solution to prevent its occurrence.

During LSG, the nasogastric tube is pernasally inserted and is not entirely removed during gastric section. Its extremity stays in the cavum and the calibrating bougie is introduced trough the mouth. Therefore, in this case the calibrating bougie led the nasogastric tube to the stomach. To avoid this kind of accident, we now systematically insert the nasogastric tube by mouth through a Guedel cannula. To insert the calibrating bougie we must entirely withdraw the nasogastric tube.

When this situation occurs, surgery must be systematically associated with endoscopic removal of the remnant nasogastric tube: indeed, its ablation can create a staple line defect. The gastric wall is subsequently repaired by the surgeon and the methylene blue test is systematically performed in order to prevent staple line leak.

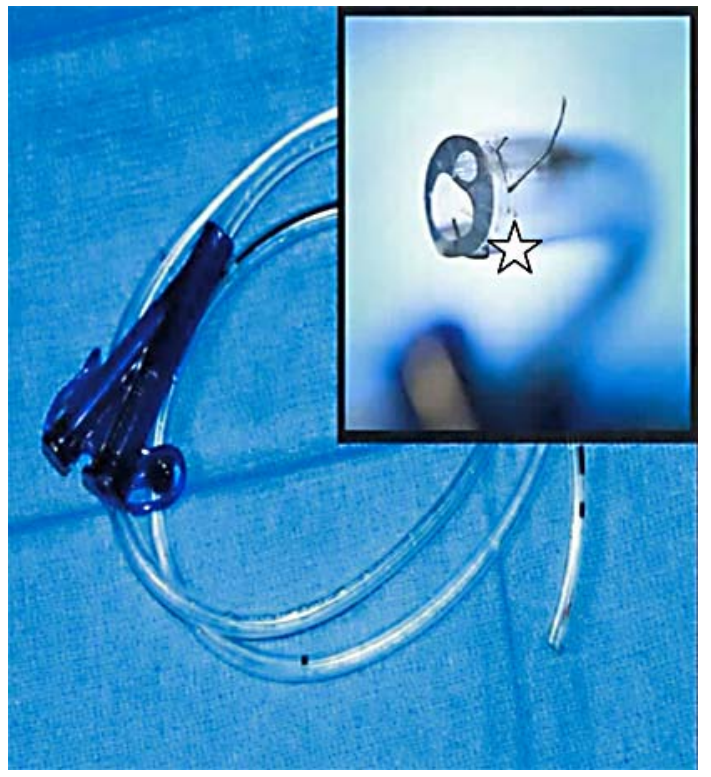

Fig. 1. In the recovery room, the nurse observes that the nasogastric tube was shorter, with staples fixed on its extremity ( $\lesssim$ ). 


\begin{tabular}{r|l|l|l}
$\begin{aligned} \text { Case Reports in } \\
\text { Gastroenterology }\end{aligned}$ & $\begin{array}{l}\text { Case Rep Gastroenterol 2011;5:350-354 } \\
\text { DOl: 10.1159/000329706 }\end{array}$ & $\begin{array}{l}\text { Published online: } \\
\text { July 6, 2011 }\end{array}$ & $\begin{array}{l}\text { O 2011 S. Karger AG, Basel } \\
\text { ISSN 1662-0631 } \\
\text { www.karger.com/crg }\end{array}$ \\
\hline
\end{tabular}

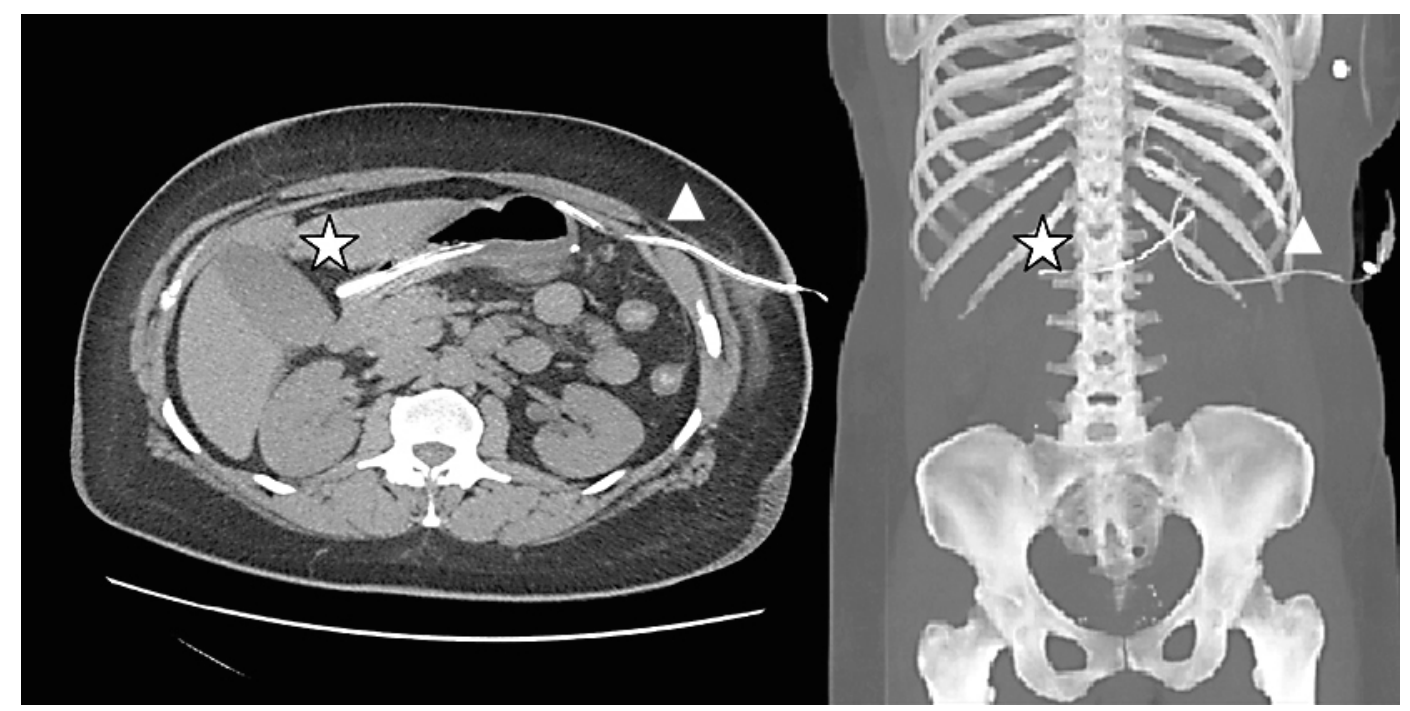

Fig. 2. Tomographic imaging with $3 \mathrm{D}$ reconstruction. The remnant nasogastric fragment $(\Sigma)$ is located in the antrum, and the abdominal drain $(\triangle)$ against the gastric staple line.

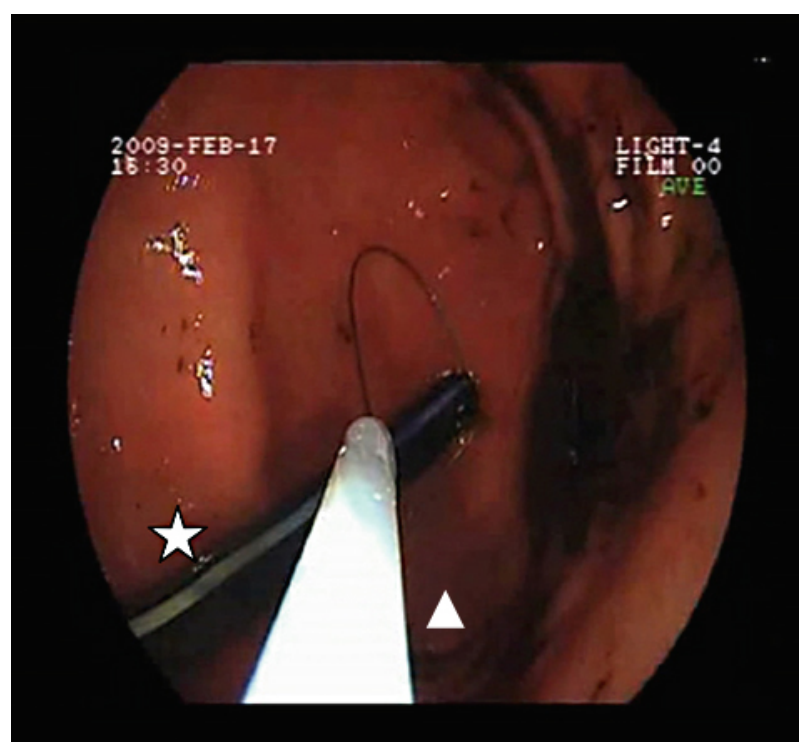

Fig. 3. Endoscopic extraction of the remnant nasogastric tube. The remnant fragment of the nasogastric tube $(\xi)$ is localised endoscopically and extracted with an endoscopic loop $(\triangle)$. This approach is completed by the surgeon, who performs laparoscopic suturing of the staple line defect. 


\begin{tabular}{r|l|l|l}
$\begin{array}{r}\text { Case Reports in } \\
\text { Gastroenterology }\end{array}$ & $\begin{array}{l}\text { Case Rep Gastroenterol 2011;5:350-354 } \\
\text { DOl: 10.1159/000329706 }\end{array}$ & $\begin{array}{l}\text { Published online: } \\
\text { July 6, 2011 }\end{array}$ & $\begin{array}{l}\text { @ 2011 S. Karger AG, Basel } \\
\text { ISSN 1662-0631 } \\
\text { www.karger.com/crg }\end{array}$ \\
\hline
\end{tabular}

\section{References}

$\checkmark 1$ Sjostrom L, Lindroos A, Peltonen M, et al: Lifestyle, diabetes, and cardio-vascular risk factors 10 years after bariatric surgery. N Engl J Med 2004;351:2683-2693.

2 Buchwald H, Avidor Y, Braunwald E, et al: Bariatric Surgery. A systemic review and meta-analysis. JAMA 2004;292:1724-1737.

-3 Sjostrom L, Narbro K, Sjostrom CD, et al: Swedish Obese Subjects Study. Effects of bariatric surgery on mortality in Swedish obese subjects. N Engl J Med 2007;357:741-752.

4 Dhahri A, Qassemyar Q, Verhaeghe P, Dessailloud-Godard R, Badaoui R, Regimbeau JM: Bariatric surgery in the treatment of severe obesity. Rev Prat 2009;59:1198-1203.

5 Haute Autorité de la Santé: Obésité: prise en charge chirurgicale chez l'adulte. Recommandations pour la pratique clinique. January 2009.

-6 Sabbagh C, Verhaeghe P, Dhahri A, Brehant O, Fuks D, Badaoui R, Regimbeau JM: Two-Year results on morbidity, weight loss and quality of life of sleeve gastrectomy as first procedure, sleeve gastrectomy after failure of gastric banding and gastric banding. Obes Surg 2010;20:679-684.

7 Dixon JB, O'Brien PE: Health outcomes of severely obese type 2 diabetic subjects 1 year after laparoscopic adjustable gastric banding. Diabetes Care 2002;25:358-363.

$>8$ Buchwald H, Avidor Y, Braunwald E, et al: Bariatric surgery: A systematic review and meta-analysis. JAMA 2004;292:1724-1737.

-9 Cottam D, Qureshi FG, Mattar SG, et al: Laparoscopic sleeve gastrectomy as an initial weight-loss procedure for high-risk patients with morbid obesity. Surg Endosc 2006;20:859-863.

10 Silecchia G, Boru C, Pecchia A, et al: Effectiveness of laparoscopic sleeve gastrectomy (first stage of biliopancreatic diversion with duodenal switch) on co-morbidities in super-obese high-risk patients. Obes Surg 2006;16:1138-1144.

11 Cull CA, Jensen CC, Retnakaran R, Holman RR: Impact of the metabolic syndrome on macrovascular and microvascular outcomes in type 2 diabetes mellitus: United Kingdom Prospective Diabetes Study 78. Circulation 2007;116:2119-2126.

12 Frezza E, Worniak S, Gee L: Complications after laparoscopic sleeve gastrectomy for morbid obesity. Obes Surg 2009;19:684-687.

13 Fuks D, Dumont F, Berna P, Verhaeghe P, Sinna R, Sabbagh C, Demuynck F, Yzet T, Delcenserie R, Bartoli E, Regimbeau JM: Case report - complex management of a postoperative bronchogastric fistula after laparoscopic sleeve gastrectomy. Obes Surg 2009;19:261-264.

14 Deguines JB, Qassemyar Q, Dhahri A, Brehant O, Fuks D, Verhaeghe P, Regimbeau JM: Technique of open laparoscopy for supramesocolic surgery in obese patients. Surg Endosc 2010;24:2053-2055.

15 Verhaeghe P, Dhahri A, Qassemyar Q, Regimbeau JM: Technique de la gastrectomie longitudinale (sleeve gastrectomy) par laparoscopie; in: Encyclopédie médico-chirurgicale. Techniques chirurgicales - appareil digestif. Paris, Elsevier Masson SAS, 2011, pp 40-385. 